\title{
Nintedanib allows retreatment with atezolizumab of combined non-small cell lung cancer/idiopathic pulmonary fibrosis after atezolizumab-induced pneumonitis: a case report
}

Hideaki Yamakawa ${ }^{1,2^{*}}$ (D) Tomohiro Oba ${ }^{1}$, Hiroki Ohta ${ }^{1}$, Yuta Tsukahara', Gen Kida ${ }^{1}$, Emiri Tsumiyama ${ }^{1,2}$, Tomotaka Nishizawa', Rie Kawabe', Shintaro Sato ${ }^{1}$, Keiichi Akasaka', Masako Amano', Kazuyoshi Kuwano ${ }^{2}$ and Hidekazu Matsushima ${ }^{1}$

\begin{abstract}
Background: Nintedanib is a tyrosine kinase inhibitor that efficiently slows the progression of idiopathic pulmonary fibrosis (IPF) and has an acceptable tolerability profile. In contrast, immune checkpoint inhibitors (ICls) such as programmed death 1 and programmed death ligand 1 inhibitors have shown clinical activity and marked efficacy in the treatment of non-small cell lung cancer. However, it is unclear whether nintedanib reduces the risk of IClinduced pneumonitis in IPF.

Case presentation: A 78-year-old man with squamous cell lung carcinoma in IPF underwent second-line treatment with pembrolizumab. He was diagnosed as having pembrolizumab-induced pneumonitis after two cycles. He was administered prednisolone (PSL) and then improved immediately. Thereafter, his lung cancer lesion enlarged despite treatment with TS-1. Atezolizumab was then administered as 4th-line chemotherapy, but he immediately developed atezolizumab-induced pneumonitis after 1 cycle. The re-escalated dosage of PSL improved the pneumonitis, and then nintedanib was started as additional therapy. Under careful observation with nintedanib, atezolizumab was re-administered on day 1 of an every-21-day cycle. After three cycles, it remained stable without exacerbation of drug-induced pneumonitis.
\end{abstract}

Conclusion: This case indicates the possibility that the addition of nintedanib to $\mathrm{ICI}$ therapy might prevent druginduced pneumonitis or acute exacerbation of IPF. However, whether anti-fibrotic agents such as nintedanib are actually effective in preventing ICl-induced pneumonitis in ILD remains unknown and additional research is greatly needed to identify effective therapies for ILD combined with lung cancer.

Keywords: Nintedanib, Immune checkpoint inhibitors, Drug-induced pneumonitis

\footnotetext{
* Correspondence: hide1144@jikei.ac.jp

'Department of Respiratory Medicine, Saitama Red Cross Hospital, 1-5

Shintoshin, Chuo-ku, Saitama, Saitama 330-8553, Japan

2Department of Respiratory Medicine, Tokyo Jikei University Hospital, Tokyo,

Japan
}

(c) The Author(s). 2019 Open Access This article is distributed under the terms of the Creative Commons Attribution 4.0 International License (http://creativecommons.org/licenses/by/4.0/), which permits unrestricted use, distribution, and

reproduction in any medium, provided you give appropriate credit to the original author(s) and the source, provide a link to the Creative Commons license, and indicate if changes were made. The Creative Commons Public Domain Dedication waiver (http://creativecommons.org/publicdomain/zero/1.0/) applies to the data made available in this article, unless otherwise stated. 


\section{Background}

The treatment of advanced non-small cell lung cancer (NSCLC) has evolved to include targeted therapy, immune checkpoint inhibitors (ICIs), and chemotherapy for selected patients in the first-line setting. Angiogenesis inhibitors have been used in combination with chemotherapy in the first-line and maintenance settings to provide improved progression-free survival, objective response rate, and overall survival in selected studies. A biologic rationale exists for combining anti-angiogenic agents with immunotherapy and targeted kinase inhibitors [1]. ICIs aid in enhancing antitumor activities, and as a byproduct they can also stimulate the immune system, resulting in immune-related adverse events such as ICI-related pneumonitis. This is contributed to by patients' smoking history, damage to underlying lung parenchyma, chronic obstructive pulmonary disease, and pulmonary fibrosis [2-5].

Nintedanib is a tyrosine kinase inhibitor that efficiently slows the progression of idiopathic pulmonary fibrosis (IPF) and has an acceptable tolerability profile [6]. Treatment with nintedanib reduces the risk of acute exacerbations (AEs), and a combined analysis of data from clinical trials of nintedanib shows a trend towards a reduction in mortality [7]. Moreover, a study such as J-SONIC is ongoing to evaluate the efficacy and safety, including AE of IPF (AE-IPF), of nintedanib combined with cytotoxic drugs compared with cytotoxic drugs alone for chemotherapy-naïve patients with IPF combined with NSCLC [8]. However, it is unclear whether nintedanib reduces the risk of ICI-induced pneumonitis of IPF. We herein report a case of NSCLC combined with IPF in which recurrence of ICI-induced pneumonitis may have been prevented with nintedanib therapy.

\section{Case presentation}

\section{Case report}

We present the case of a 78-year-old man, a former smoker, with squamous cell lung carcinoma. Clinical staging was stage IV [cT3N2M1c (ADR)]. He was simultaneously diagnosed as having interstitial pneumonia. Chest high-resolution computed tomography (CT) showed a mass lesion of the right upper lobe as the primary lung carcinoma that was surrounded by ground-glass opacities as carcinomatous lymphangiomatosis. Interstitial pneumonia, as indicated by a subpleural reticular shadow with traction bronchiectasis and bronchiolectasis predominantly in the lower lobes and without apparent honeycombing, was comparable with probable usual interstitial pneumonia pattern based on recent criteria [9] (Fig. 1a). He had no symptoms suspicious of connective tissue disease and serological domain as all auto-antibodies. In addition, he had no history of exposure-evoked aspects of chronic hypersensitivity pneumonitis or familial or chronic drug-induced pneumonitis.

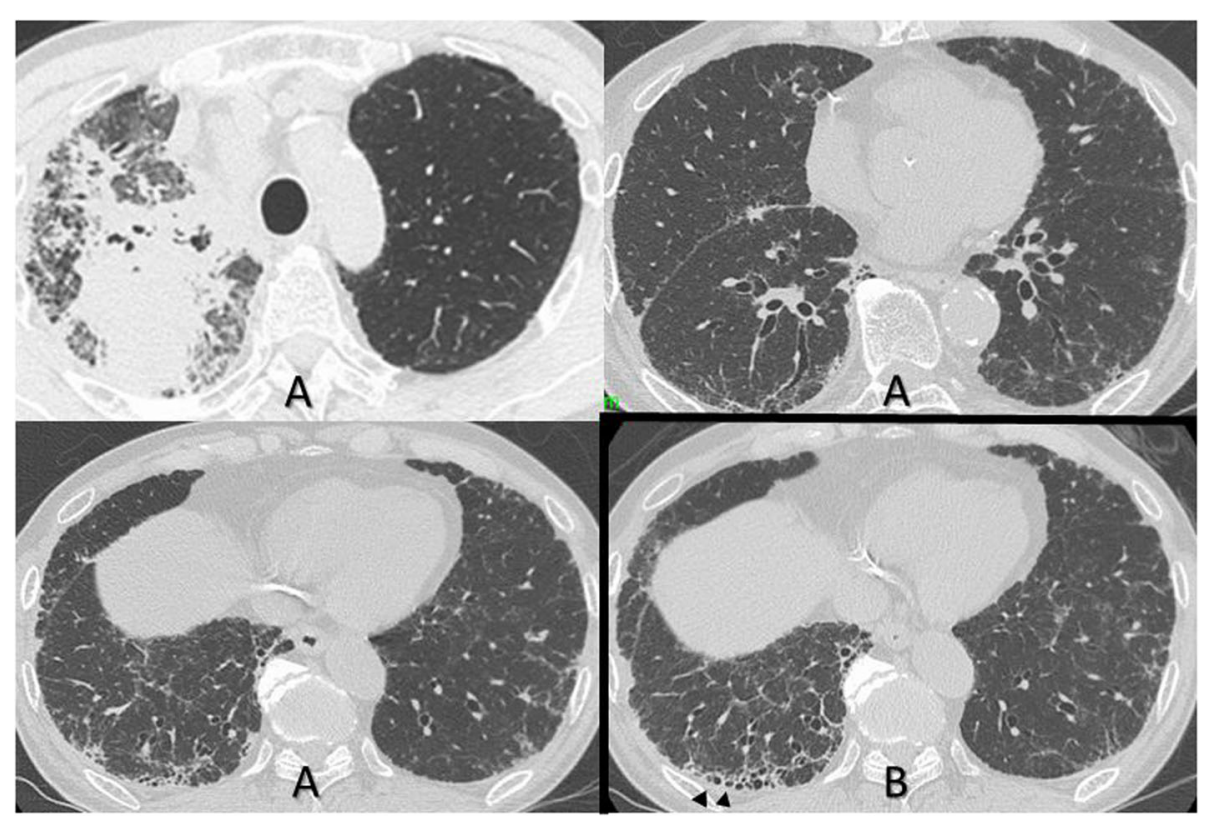

Fig. 1 (a) Chest high-resolution computed tomography performed at initial presentation showed a mass lesion in the right upper lobe as the primary lung cancer and interstitial abnormality predominantly in the lower lobe. The interstitial abnormality was basal predomoinant and showed reticulation with peripheral traction bronchiectasis and bronchioloectasis, which was probably compatible with usual interstitial pneumonia pattern. (b) One year and 3 months after initial presenteation, honeycomb lesions appeared in the lower lobe (arrowheads) 
The patient underwent first-line treatment with carboplatin and nab-paclitaxel from May 201X. After 4 cycles, disease progression was recognized. Therefore, secondline chemotherapy of pembrolizumab was administered. However, CT revealed bilateral ground-glass opacities and his serum levels of Krebs von den Lungen-6 (KL-6) were increased, although the size of the lung cancer tumors was reduced after 2 cycles (Fig. 2). We diagnosed pembrolizumab-induced pneumonitis and then started prednisolone (PSL) at $30 \mathrm{mg} /$ day. This pulmonary toxic lesion began to improve immediately, and the dose of PSL was gradually tapered to $2.5 \mathrm{mg} /$ day in April $201 \mathrm{X}+1$. Because of apparent regrowth of the cancerous lesion with brain metastasis, stereotaxic radiation of brain lesions and tegafur/gimeracil/oteracil (TS-1) as third-line chemotherapy were administered. However, disease progression was confirmed. At one year and 3 months after his initial presentation (August 201X +1 ), honeycomb lesions appeared in the lower left lobe (Fig. 1b). Therefore, we diagnosed IPF because the radiological disease course became one of typical usual interstitial pneumonia and the patient had no evidence indicating other etiologies.
After careful examination of the drug-induced pneumonitis, atezolizumab was administered as fourth-line chemotherapy, but the patient developed subacute atezolizumab-induced pneumonitis after 1 cycle. A re-escalated dosage of PSL improved his pneumonitis, and his serum levels of KL-6 decreased, following which nintedanib was started as additional therapy for the IPF. Under careful observation with nintedanib (200 mg/day) and PSL (5 mg/ day), atezolizumab was re-administered on day 1 of an every-21-day cycle. After three cycles, it remained stable without exacerbation of drug-induced pneumonitis. However, afterwards, he developed multiple brain metastases and carcinomatous meningitis. Because his therapy was converted to palliative care, he died one and a half months later due to carcinomatous meningitis.

\section{Discussion and conclusion}

Our patient developed drug-induced pneumonitis from both pembrolizumab and atezolizumab. However, the use of nintedanib allowed us to re-administer atezolizumab without further recurrence of the drug-induced pneumonitis. We highlight the possibility of using nintedanib to

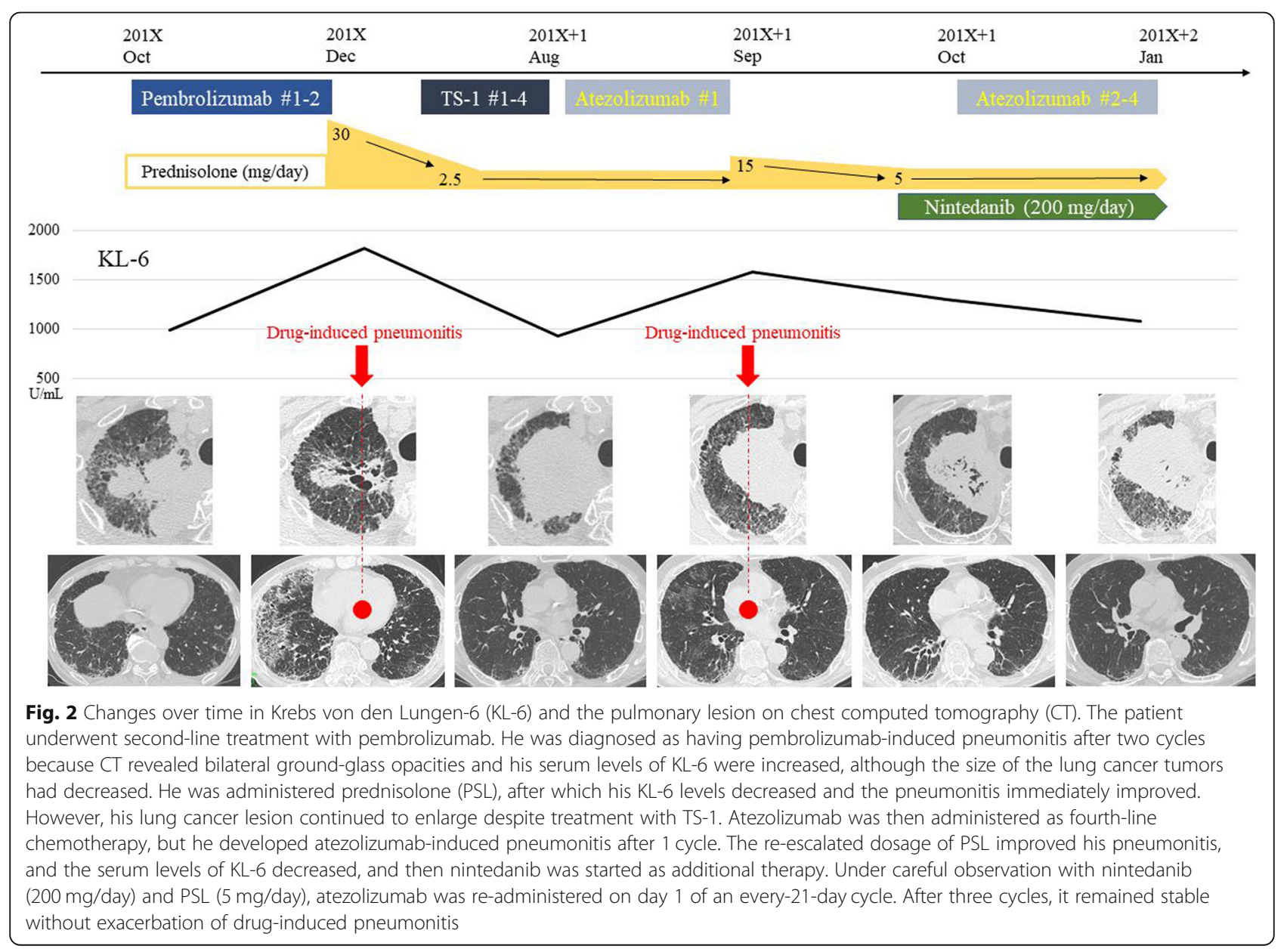


prevent atezolizumab-induced pneumonitis in IPF combined with lung cancer. ICIs such as programmed death 1 (PD-1) and PD ligand 1 inhibitors have shown clinical activity and marked efficacy in the treatment of NSCLC [10]. Pembrolizumab as a PD-1 inhibitor and atezolizumab as a PD ligand 1 inhibitor were used in our patient. Certain ICI-related adverse events have been observed related to the skin, gastrointestinal tract, endocrine system, liver, lungs, and kidneys $[11,12]$. Drug-induced pneumonitis has been reported as one of the most common lungrelated immunological adverse events with an incidence ranging between 1 and 5\% [10]. With nivolumab as a PD1 inhibitor, the clinical course of most patients with nivolumab-induced pneumonitis was relatively good following the cessation of nivolumab and the initiation of a corticosteroid. It is noteworthy that two thirds of patients with nivolumab-induced pneumonitis were able to restart their nivolumab therapy [13]. However, one third of patients developed recurrent pneumonitis. It is not clear which subgroup among the patients with ICI-related pneumonitis will suffer the recurrence of pneumonitis. However, existing interstitial pneumonia is a known risk factor of ICI-related pneumonitis [2-5]. Moreover, AE-IPF, as in our case, is a severe and life-threatening complication [14]. AE-IPF is triggered by various causes such as infection, post-procedural/postoperative period, drug toxicity, and aspiration [14]. Although the direct relevance remains unknown, ICIs may be an important trigger in AE-IPF. Our patient developed drug-induced pneumonitis with both pembrolizumab and atezolizumab, and moreover, the atezolizumab-induced pneumonitis occurred immediately. Because of this clinical course and co-existing IPF, we thought our patient was at high risk for recurrence of serious ICI-induced pneumonitis or AE-IPF. Therefore, we hypothesized that nintedanib might allow re-administration of atezolizumab without recurrence of drug-induced pneumonitis.

Nintedanib has a number of clinical benefits in patients with IPF, such as reducing the decline of lung function and extending the time to AE [7]. Nintedanib is an oral angiokinase inhibitor that targets receptors in three proangiogenic pathways: vascular endothelial growth factor (VEGF) receptors, platelet-derived growth factor receptors $\alpha / \beta$, and fibroblast growth factor receptors. Therefore, this drug has been expected to have an anti-tumor effect on lung cancer [15]. In fact, combination therapy with nintedanib and docetaxel significantly improved independently assessed progression-free survival compared with placebo/docetaxel in the overall LUME-Lung-1 study population and provided significant, clinically meaningful improvement in overall survival in patients with adenocarcinoma [16]. This study showed that the rates of occurrence of drug-induced pneumonitis did not differ between the nintedanib and placebo groups (1.4 and $0.8 \%$, respectively). However, the J-SONIC trial, a randomized control study for the treatment of NSCLC associated with IPF, showed that nintedanib combined with carboplatin plus nab-paclitaxel prolonged the interval to AE-IPF compared with carboplatin plus nab-paclitaxel alone [8]. That is, nintedanib was thought to be a key drug in the treatment of lung cancer combined with IPF. On the other hand, the excessive autoimmune response of tumor infiltrating lymphocytes can be the one of the reasons of ICI-induced pneumonitis [17]. VEGF can act as an immunosuppressive factor by several mechanisms such as inhibiting dendric cell (DC) function and maturation, enhancing expression of PD-L1 by DCs, promoting into the tumor [18]. Therefore, nintedanib that the target the VEGF pathway may enhance the prevention of ICI-induced pneumonitis. Unfortunately, the combination of nintedanib with atezolizumab showed no anti-tumor effectiveness in our case. However, although there have never been trials of combination treatment of ICIs and nintedanib until now, to the best of our knowledge, this combination therapy may improve the safety and survival of lung cancer associated with IPF.

In conclusion, our case indicates the possibility that ICIs combined with nintedanib might prevent drug-induced pneumonitis or AE-IPF. However, whether anti-fibrotic agents such as nintedanib are actually effective in the prevention of ICI-induced pneumonitis in ILD remains unknown, and additional research is greatly needed to identify effective therapies for ILD combined with lung cancer.

\footnotetext{
Abbreviations

AE: Acute exacerbation; CT: Computed tomography; DC: Dendric cell; ICls: Immune checkpoint inhibitors; IPF: Idiopathic pulmonary fibrosis; KL6: Krebs von den Lungen-6; NSCLC: Non-small cell lung cancer; PD1: Programmed death 1; PD-L1: Programmed death ligand 1;

PSL: Prednisolone; VEGF: Vascular endothelial growth factor
}

\section{Acknowledgments}

The authors would like to thank the patient's son for the informed consent to allow publication of this report. The authors would like to thank Rise Japan LLC for the professional English language review.

\section{Authors' contributions}

$\mathrm{YH}$ and $\mathrm{OT}$ were involved in the acquisition of the data; $\mathrm{YH}, \mathrm{OT}, \mathrm{OH}, \mathrm{TY}, \mathrm{KG}$, $\mathrm{TE}, \mathrm{NT}, \mathrm{KR}, \mathrm{SS}, \mathrm{AK}, \mathrm{AM}, \mathrm{KK}$ and $\mathrm{MH}$ were involved in the analysis and interpretation of the clinical data; and $\mathrm{YH}$ and $\mathrm{MH}$ were involved in the drafting of the manuscript. All authors read and approved the final manuscript.

\section{Funding}

Not applicable.

Availability of data and materials

The data will not be shared with participant confidentiality.

Ethics approval and consent to participate

Not applicable. 


\section{Consent for publication}

Written informed consent was obtained from the son of the patient for publication of this case report and any accompanying images.

\section{Competing interests}

The authors declare that they have no competing interests.

Received: 10 April 2019 Accepted: 15 August 2019

Published online: 22 August 2019

\section{References}

1. Perdrizet $\mathrm{K}$, Leighl NB. The role of angiogenesis inhibitors in the era of immune checkpoint inhibitors and targeted therapy in metastatic non-smal cell lung cancer. Curr Treat Options in Oncol. 2019;20:21.

2. Nishino M, Giobbie-Hurder A, Hatabu H, Ramaiya NH, Hodi F. Incidence of programmed cell death 1 inhibitor-related pneumonitis in patients with advanced cancer: a systematic review and meta-analysis. JAMA Oncol. 2016:2:1607-16.

3. Toh CK, Wong EH, Lim WT, Leong SS, Fong KW, Wee J. The impact of smoking status on the behavior and survival outcome of patients with advanced non-small cell lung cancer: a retrospective analysis. Chest. 2004; 126:1750-6.

4. Bouros D, Hatzakis K, Labrakis H, Zeibecoglou K. Association of malignancy with diseases causing interstitial pulmonary changes. Chest. 2002;121:1278-89.

5. Coussens LM, Werb Z. Inflammation and cancer. Nature. 2002;420:860-7.

6. Crestani B, Huggins JT, Kaye M, Costabel U, Glaspole I, Ogura T, et al. Longterm safety and tolerability of nintedanib in patients with idiopathic pulmonary fibrosis: results from the open-label extension study, INPULSIS-ON. Lancet Respir Med. 2019;7:60-8.

7. Richeldi L, du Bois RM, Raghu G, Azuma A, Brown KK, Costabel U, et al. Efficacy and safety of nintedanib in idiopathic pulmonary fibrosis. N Engl J Med. 2014;370:2071-82.

8. Otsubo K, Kishimoto J, Kenmotsu H, Minegishi Y, Ichihara E, Shiraki A, et al. Treatment rationale and design for J-SONIC: a randomized study of carboplatin plus nab-paclitaxel with or without nintedanib for advanced non-small-cell lung cancer with idiopathic pulmonary fibrosis. Clin Lung Cancer. 2018;19:e5-9.

9. Raghu G, Remy-Jardin M, Myers JL, Richeldi L, Ryerson CJ, Lederer DJ, et al. Diagnosis of Idiopathic Pulmonary Fibrosis. An Official ATS/ERS/ JRS/ALAT Clinical Practice Guideline. Am J Respir Crit Care Med. 2018:198:e44-68.

10. Khunger $M$, Jain P, Rakshit S, Pasupuleti V, Hernandez AV, Stevenson J, et al. safety and efficacy of pd-1/pd-I1 inhibitors in treatment-naive and chemotherapy-refractory patients with non-small-cell lung cancer: a systematic review and meta-analysis. Clin Lung Cancer. 2018;19:e335-48.

11. Nishino M, Sholl LM, Hodi FS, Hatabu H, Ramaiya NH. Anti-PD-1-related pneumonitis during cancer immunotherapy. N Engl J Med. 2015;373:288-90.

12. Michot JM, Bigenwald C, Champiat S, Collins M, Carbonnel F, Postel-Vinay S, et al. Immune-related adverse events with immune checkpoint blockade: a comprehensive review. Eur J Cancer. 2016;54:139-48.

13. Nishino M, Ramaiya NH, Awad MM, Sholl LM, Maattala JA, Taibi M, et al. PD-1 inhibitor-related pneumonitis in advanced cancer patients: radiographic patterns and clinical course. Clin Cancer Res. 2016;22: 6051-60

14. Collard HR, Ryerson CJ, Corte TJ, Jenkins G, Kondoh Y, Lederer DJ, et al. Acute exacerbation of idiopathic pulmonary fibrosis. An international working group report. Am J Respir Crit Care Med. 2016;194:265-75.

15. Hilberg F, Roth GJ, Krssak M, Kautschitsch S, Sommergruber W, TontschGrunt $U$, et al. BIBF 1120: triple angiokinase inhibitor with sustained receptor blockade and good antitumor efficacy. Cancer Res. 2008:68:4774-82.

16. Reck M, Kaiser R, Mellemgaard A, Douillard JY, Orlov S, Krzakowski M, et al. Docetaxel plus nintedanib versus docetaxel plus placebo in patients with previously treated non-small-cell lung cancer (LUME-Lung 1): a phase 3, double-blind, randomised controlled trial. Lancet Oncol. 2014;15:143-55.
17. Suresh K, Naidoo J, Lin CT, Danoff S. Immune checkpoint immunotherapy for non-small cell lung Cancer: benefits and pulmonary toxicities. Chest. 2018;154:1416-23.

18. Reguera-Nuñez E, Xu P, Chow A, Man S, Hilberg F, Kerbel RS. Therapeutic impact of Nintedanib with paclitaxel and/or a PD-L1 antibody in preclinical models of orthotopic primary or metastatic triple negative breast cancer. J Exp Clin Cancer Res. 2019;38:16.

\section{Publisher's Note}

Springer Nature remains neutral with regard to jurisdictional claims in published maps and institutional affiliations.
Ready to submit your research? Choose BMC and benefit from:

- fast, convenient online submission

- thorough peer review by experienced researchers in your field

- rapid publication on acceptance

- support for research data, including large and complex data types

- gold Open Access which fosters wider collaboration and increased citations

- maximum visibility for your research: over $100 \mathrm{M}$ website views per year

At $\mathrm{BMC}$, research is always in progress.

Learn more biomedcentral.com/submissions 